\title{
Effect of different river water quality model concepts used for river basin management decisions
}

\author{
V. Vandenberghe*, A. van Griensven*, W. Bauwens** and P.A. Vanrolleghem* \\ *Department of Applied Mathematics, Biometrics and Process Control, Ghent University, BIOMATH, \\ Coupure Links 653, B-9000 Ghent, Belgium (Email: veronique.vandenberghe@biomath.ugent.be) \\ **Laboratory of Hydrology and Hydraulic Engineering, Free University of Brussels, Pleinlaan 2, B-1050 \\ Brussels, Belgium
}

\begin{abstract}
In this research the applicability of two different water quality concepts, a QUAL2E-based and a RWQM1-based water quality model is evaluated in terms of management decisions. The Dender river in Belgium serves as a case study for the application of the methodology. By using sensitivity analysis on both model concepts the important processes are revealed. Further, the differences between the predictions for a future scenario are analysed. The scenario chosen here is a reduction in fertiliser use of $90 \%$, which reduces the diffuse pollution. This way, the advantages or disadvantages of using one concept against the other for this scenario are formulated. It was found that the QUAL-based models are more focussing on algae processes while the RWQM1 also takes into account processes in the sediment. Further the QUAL-based models are easier to calibrate, especially when only a small amount of data is available. Both concepts lead to more or less the same conclusions. However for some periods the differences become important and to reduce the uncertainty in those periods, more efforts should be spent in calibration and in better detection of parameters concerning sediment processes and diffusion.
\end{abstract}

Keywords Diffuse pollution; QUAL2E; river basin management; river water quality model; RWQM1

\section{Introduction}

For integrated water quality management, a holistic approach is necessary at river basin scale. As diffuse pollution sources are increasingly responsible for water quality problems, water quality modelling entered the field of catchment modelling. Upscaling of agricultural field-scale modelling tools or the inclusion of erosion and nutrient equations in catchment hydrological models has led to a number of tools that enable the calculation of the contributions of water, nutrients and sediments from drained areas. In integrated river water quality modelling, the in-stream processes play a key role, as it is here that the pollutions of different origins are added and are transformed to what finally determines the water quality.

Within the Soil and Water Assessment Tool (SWAT) (Arnolds et al., 1996), the original water quality module - based on QUAL2E (Brown and Barnwell 1987) - appeared to be erroneously implemented. Time steps of only 1 day were possible that cannot be used in evaluating river water quality processes that change on a sub-daily time base. Therefore, two alternative formulations using hourly time steps based on the QUAL2E and the more elaborated River Water Quality Model nr. 1 (RWQM1) (Reichert et al., 2001) were incorporated in the SWAT model codes and applied on the highly polluted Dender river basin (Belgium) (van Griensven and Bauwens, 2001). Since these concepts represent different processes or different formulations of the processes (see Table 1), they may give rise to different results. This is revealed when the two models are applied to pollution abatement scenarios. When using water quality models for management purposes it is important to have knowledge of the key processes in the river system. 
Table 1 Comparison between QUAL2E and RWQM1 based water quality models

\begin{tabular}{ll}
\hline QUAL2E & RWQM1 \\
\hline Effect focused & Based on activated sludge model concept \\
No microbial masses modelled & Cause focused \\
Simple & Microbial masses modelled \\
Few parameters and variables & Complex \\
Not closed mass balance & Many parameters and variables \\
\hline
\end{tabular}

To this end a sensitivity analysis (SA) on the parameters of both concepts was performed. With the results of this SA, one is able to define the restrictions of use of a certain river water quality model, e.g. when the model results are not sensitive towards sediment processes, this model cannot be used for the evaluation of anti-erosion measures.

To show the effects on management decision, a specific scenario is evaluated in which the pollution load to the river Dender originating from agricultural fertilizer use is diminished. Both river water quality concepts were used to evaluate the decrease in diffuse pollution input and a comparison is made in this study.

\section{Case study: the Dender basin}

The Dender river, a tributary of the river Scheldt in Belgium, drains an area of $1384 \mathrm{~km}^{2}$. The flow of the river is very irregular with high peak discharges $\left(100 \mathrm{~m}^{3} / \mathrm{s}\right)$ during intense rainfall and very low discharges $\left(1 \mathrm{~m}^{3} / \mathrm{s}\right)$ during dry periods. To suit navigation and to temper the high flows, the Dender is canalized and regulated by 14 sluices. Due to this, during dry periods the river reacts as a succession of reservoirs with a typical depth of $3-5 \mathrm{~m}$, a width of $12-50 \mathrm{~m}$ and lengths of $2-8 \mathrm{~km}$. In periods of high flow, all sluices are opened and the river regains its natural stream profile (Bervoets et al., 1989). The river is heavily polluted by domestic, industrial and agricultural pollution (Demuynck et al. 1997).

\section{ESWAT}

ESWAT is an extension of SWAT (van Griensven and Bauwens, 2005) the Soil and Water Assessment Tool developed by the USDA (Arnolds et al., 1996). ESWAT was developed to allow for an integrated modelling of the water quantity and quality processes in river basins. Two possibilities for the calculation of the water quality were added in the extended version. The first is QUAL2E-based, the second option is the RWQM1 model. For both the choice exists between an hourly or daily time step. Also the point sources were made dynamic which allows one to take into account pollution coming form the urban drainage system.

\section{Methodology}

The capabilities of the two different concepts of river water quality modelling to predict and assess the effects of future scenarios for pollution abatement are explored by studying a reduction in diffuse pollution load towards the river Dender. The ESWAT model was calibrated for the two water quality model concepts with two weekly measurements taken in 1994. The calibration was done with the multi-objective calibration method described in van Griensven and Bauwens (2003). The calibration of the flow was also done by multi-objective calibration, parameters calibrated were hydraulic conductivity of the soils, canopy index infiltration runoff time lagging, groundwater parameters and routing parameters. The calibration led to an efficiency of 0.9 for the flow. For both concepts, 
the results are given for the time series of $\mathrm{NO}_{3}$ and DO. SA on the models is performed on the model results for 1994 as well as the model results obtained after decreasing the diffuse pollution input. This SA is done following the methodology of Vandenberghe et al. (2001). Here a global SA is performed to see the most influential parameters of the water quality model. The method used is a regression and correlation technique (Saltelli et al., 2000) with Latin Hypercube Monte Carlo sampling (McKay, 1995). Regression is done between the parameters and the output. This output is chosen depending on the problem. Because one of the problems in the river Dender is oxygen shortage during some periods of the year, due to eutrophication, and the diffuse pollution is influencing the nitrate content of the river, nutrient for the algae, the critical output considered here is the amount of hours that the oxygen concentration drops below $5 \mathrm{mg} / \mathrm{l}$ and the nitrate concentration is higher than $3 \mathrm{mg} / \mathrm{l}$.

The standardized regression coefficients (SRCs) are used as sensitivity measures:

$\operatorname{SRC}_{\mathrm{i}} \frac{\Delta y / S_{y}}{\Delta x_{i} / S_{x_{i}}}$

with $\Delta y / \Delta x_{i}=$ change in output $(\Delta y)$ due to a change in an input factor $\left(\Delta x_{i}\right)$ and $S_{y}, S_{x_{i}}$ are the standard deviation of the output and the input respectively. The input standard deviation $S_{x_{i}}$ is specified by the user.

Ranking of the parameters is done according to the SRC. Only the parameters contributing significantly in this linear regression ( $90 \%$ level) are presented.

The SA on the base scenario reveals which processes will be taken into account when computing predictions for the abatement scenarios. The SA on the scenario shows the importance of the changed input on the modelled processes. It helps to decide what processes have to be measured and evaluated for attaining more reliable results of the model when evaluating a future scenario.

\section{Results}

Time series

The base case with real input of the year 1994 and the scenario with $90 \%$ fertiliser use reduction are presented in Figures 1 to 4 . In Figures 1 and 2 the $\mathrm{DO}$ and $\mathrm{NO}_{3}$ time series with a QUAL2E model concept are given at Denderbelle, a place close to the mouth of the river. Figures 3 and 4 give the time series at the same place as a result of simulations with the RWQM1 model.

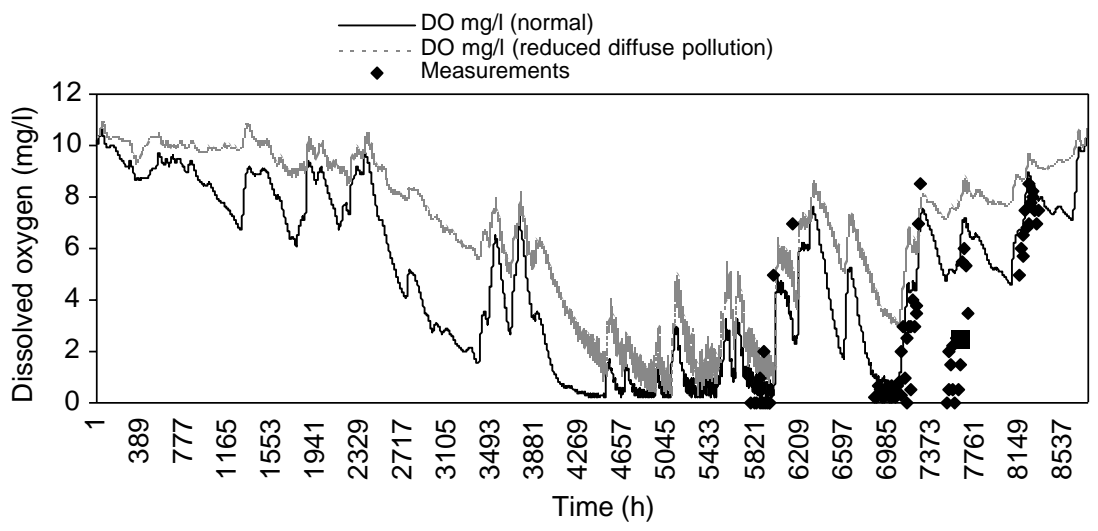

Figure 1 Time series 1994 (normal and scenario reduction diffuse pollution) with measurements in 1994 


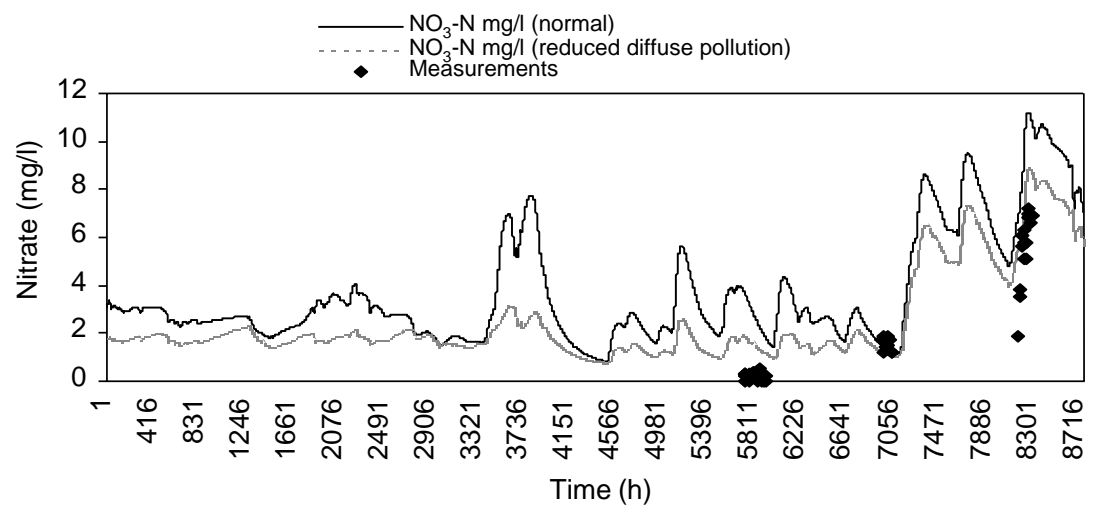

Figure 2 Time series 1994 (normal and scenario reduction diffuse pollution) with measurements in 1994 for $\mathrm{NO}_{3}$ at Denderbelle, simulated with QUAL2E based model

From the comparison between the different time series modeled with the two water quality concepts, it can be concluded that the dissolved oxygen profile of the base case and the reduction scenario is approximately the same for both model concepts. At least the general tendency is the same, although there are periods with large differences e.g. more variation because of algae photosynthesis and respiration with Qual2E and lower DO around hour 7700 for RWQM1. But for the nitrate concentration in the river, the profiles are rather different. It was also found that the RWQM1 model is difficult to calibrate for all variables. The mass balance is closed here and by calibrating with data on DO, $\mathrm{BOD}, \mathrm{NO}_{3}, \mathrm{NO}_{2}, \mathrm{NH}_{4}$ and $\mathrm{PO}_{4}$ it is not possible to find a very good fit for all of them. More and more accurate data are needed to obtain better results. It can be concluded that the QUAL2E model with its lumping of processes of different microbial communities is easier to calibrate with less data.

Comparing the results of the scenarios, the same conclusions will be drawn from both model results on dissolved oxygen. Lowering the diffuse pollution towards the river is not a solution by itself as the nutrients coming from households are still high and still lead to algae growth during the summer, with extremely low oxygen concentrations. For nitrates the conclusions with RWQM1 are more optimistic, showing that nitrates are much lower in the river during the whole year, Due to the importance here of denitrification in the sediment too, nitrates are lowered. In the reduction scenario, the SA for

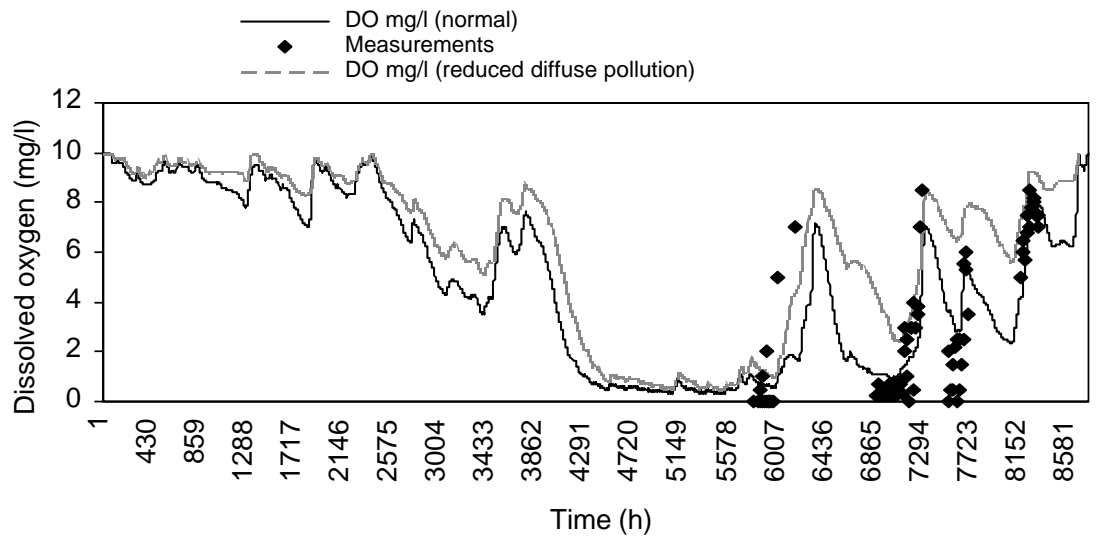

Figure 3 Time series 1994 (normal and scenario reduction diffuse pollution) with measurements in 1994 for DO at Denderbelle, simulated with RWQM1 based model 


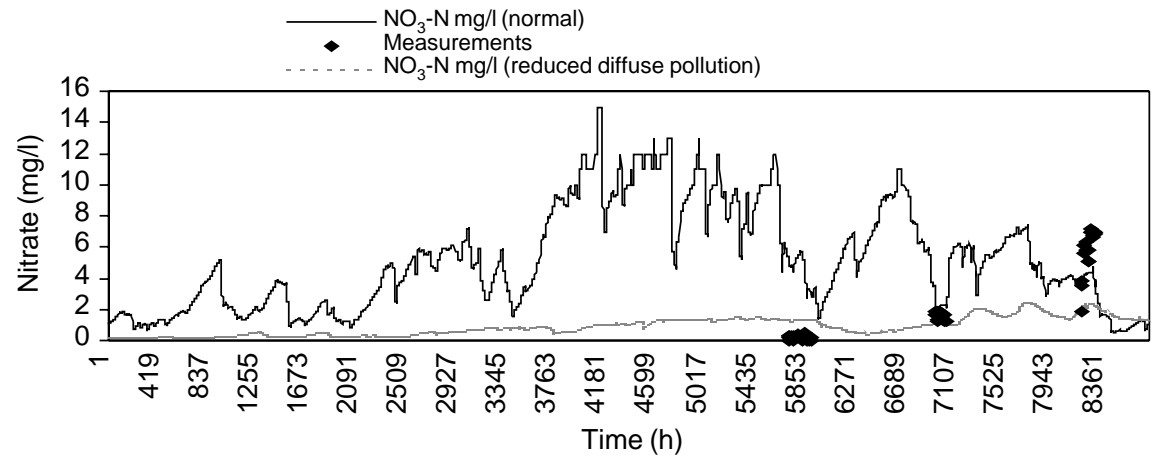

Figure 4 Time series 1994 (normal and scenario reduction diffuse pollution) with measurements in 1994 for $\mathrm{NO}_{3}$ at Denderbelle, simulated with RWQM1 model

RWQM1 (Table 5) shows that sedimentation and diffusion processes become even more important. So, to attain more accurate results with more reliability, special attention will be needed towards the calibration and validation of those processes if a RWQM1 model is used. For the QUAL2E model too the settling processes come more into the picture (Table 4 compared to Table 2) showing the importance of the sediments when input of nitrates and phosphates decrease.

When looking at diffuse pollution abatement scenarios, algae play an important role as the amount of nutrients used by algae for growth ( $\mathrm{P}$ and $\mathrm{N}$ ) come mainly from agricultural fertilizer use. In this study, the difference between the modeling approach towards algae growth only becomes relevant when in the future scenario point pollution loads are diminished as well. In the Dender case it appears that the nutrients never become limiting, and algae growth continues with increased temperature and solar radiation. Consequently the differences in dissolved oxygen profiles between base and reduction scenarios are not really clear. Processes that are of importance are denitrification in the water and in the sediments.

\section{Sensitivity analysis}

Tables 2-5 gives the result of the SA on the base case and the scenario of reduced diffuse pollution. The results of the base case are similar to the results found by van Griensven and Vanrolleghem (2005) with a one factor-at-the-time method for sensitivity analysis. It can be concluded that QUAL2E is suited for evaluations related to algae while RWQM1 is better representing the settling and river bed interactions, and the microbial dynamics/limiting factors. The results of the SA for the reduction scenarios

Table 2 Ranking of sensitivity of parameters of QUAL2E model based on SRC for the output $\mathrm{NO}_{3}>3 \mathrm{mg} / \mathrm{l}$ and DO $<5 \mathrm{mg} / \mathrm{l}$ (base case)

\begin{tabular}{|c|c|c|c|}
\hline \multicolumn{2}{|l|}{$\mathrm{NO}_{3}>3 \mathrm{mg} / \mathrm{l}$} & \multicolumn{2}{|l|}{ DO $<5$ mg/l } \\
\hline Parameter & SRC & Parameter & SRC \\
\hline $\mathrm{O}_{2}$ uptake $/ \mathrm{NH}_{3}$ oxidation & -0.704 & $\mathrm{O}_{2}$ uptake/ $/ \mathrm{NH}_{3}$ oxidation & 0.521 \\
\hline Denitrification rate & -0.342 & Rate biological oxidation of $\mathrm{NH}_{4}$ to $\mathrm{NO}_{2}$ & 0.354 \\
\hline Reaeration rate & 0.321 & $\mathrm{O}_{2}$ uptake/algae respiration & 0.279 \\
\hline $\mathrm{O}_{2}$ uptake/ $\mathrm{HNO}_{2}$ oxidation & -0.211 & CbOD deoxygenation rate & 0.268 \\
\hline Rate biological oxidation of $\mathrm{NO}_{2}$ to $\mathrm{NO}_{3}$ & -0.268 & $\mathrm{O}_{2}$ production/algae growth & -0.240 \\
\hline CBOD loss due to settling & 0.173 & Algae resp rate & 0.159 \\
\hline \multirow[t]{3}{*}{$\mathrm{O}_{2}$ uptake/algae respiration } & 0.121 & $\mathrm{O}_{2}$ uptake/ $\mathrm{HNO}_{2}$ oxidation & 0.159 \\
\hline & & Max algae growth rate & -0.159 \\
\hline & & CBOD loss due to settling & -0.149 \\
\hline
\end{tabular}


Table 3 Ranking of sensitivity of parameters of RWOM1 model based on SRC for the output $\mathrm{NO}_{3}>3 \mathrm{mg} / \mathrm{l}$ and DO $<5 \mathrm{mg} / \mathrm{l}$ (base case)

\begin{tabular}{|c|c|c|c|}
\hline \multicolumn{2}{|l|}{$\mathrm{NO}_{3}>3 \mathrm{mg} / \mathrm{l}$} & \multicolumn{2}{|l|}{ DO < mg/l } \\
\hline Parameter & SRC & Parameter & SRC \\
\hline Growth rate first-stage nitrifiers & -0.662 & Growth rate heterotrophs, aerobic & 0.482 \\
\hline Respiration rate first-stage nitrifiers & 0.341 & Respiration rate algae & 0.394 \\
\hline Respiration rate heterotrophs, aerobic & 0.150 & Respiration rate first-stage nitrifiers & 0.319 \\
\hline Respiration rate heterotrophs, anoxic & -0.145 & Growth rate algae & -0.313 \\
\hline Growth rate consumers in sediment & -0.123 & Growth rate second-stage nitrifiers & -0.260 \\
\hline Hydration rate in sediment & 0.111 & $\begin{array}{l}\text { Growth rate heterotrophs, aerobic in } \\
\text { sediments }\end{array}$ & -0.073 \\
\hline $\begin{array}{l}\text { Growth rate heterotrophs, aerobic in } \\
\text { sediments }\end{array}$ & -0.097 & Reaeration rate & -0.072 \\
\hline Respiration rate algae & 0.088 & & \\
\hline Reaeration rate & 0.086 & & \\
\hline
\end{tabular}

Table 4 Ranking of sensitivity of parameters of QUAL2E model based on SRC for the output $\mathrm{NO}_{3}>3 \mathrm{mg} / \mathrm{l}$ and $\mathrm{DO}<5 \mathrm{mg} / \mathrm{l}$ (reduced diffuse pollution)

\begin{tabular}{|c|c|c|c|}
\hline \multicolumn{2}{|l|}{$\mathrm{NO}_{3}>3 \mathrm{mg} / \mathrm{l}$} & \multicolumn{2}{|l|}{ DO < $5 \mathrm{mg} / \mathrm{l}$} \\
\hline Parameter & SRC & Parameter & SRC \\
\hline Reaeration rate & -0.728 & Reaeration rate & -0.728 \\
\hline Benthic oxygen demand & 0.360 & Rate biological oxidation of $\mathrm{NH}_{4}$ to $\mathrm{NO}_{2}$ & 0.360 \\
\hline CBOD loss due to settling & 0.229 & Bethic source rate $\mathrm{NH}_{4}$ & 0.229 \\
\hline Rate biological oxidation of $\mathrm{NH}_{4}$ to $\mathrm{NO}_{2}$ & 0.185 & Benthic oxygen demand & 0.185 \\
\hline Algae preference factor for ammonia & 0.122 & $\mathrm{O}_{2}$ uptake $/ \mathrm{NH}_{3}$ oxidation & 0.122 \\
\hline Rate org N settling & -1.00 & Rate org N settling & -1.00 \\
\hline Half-saturation constant for nitrogen & -0.083 & Algae respiration rate & -0.087 \\
\hline CBOD deoxygenation rate & 0.078 & Half-saturation constant for phosphor & -0.083 \\
\hline $\mathrm{O}_{2}$ uptake/ $/ \mathrm{NH}_{3}$ oxidation & 0.12 & & \\
\hline
\end{tabular}

indicate that due to the decreased load of nutrients to the river some processes become more or less important. For the QUAL2E model for the base case, nitrification/denitrification is important, but for the scenario the benthic oxygen demand, organic $\mathrm{N}$ settling and cBOD deoxygenation also become important. In the SA for RWQM1 the results show a shift in importance of processes more towards sediment processes and diffusion in the river water.

Table 5 Ranking of sensitivity of parameters of RWQM1 model based on standardized regression coefficient for the output $\mathrm{NO}_{3}>3 \mathrm{mg} / \mathrm{l}$ and DO $<5 \mathrm{mg} / \mathrm{l}$ (reduced diffuse pollution)

\begin{tabular}{|c|c|c|c|}
\hline \multicolumn{2}{|l|}{$\mathrm{NO}_{3}>3 \mathrm{mg} / \mathrm{l}$} & \multicolumn{2}{|l|}{$\mathrm{DO}<\mathrm{mg} / \mathrm{l}$} \\
\hline Parameter & SRC & Parameter & SRC \\
\hline Growth rate first-stage nitrifiers & -0.853 & Growth rate heterotrophs, aerobic & 0.416 \\
\hline Respiration rate first-stage nitrifiers & 0.331 & Growth rate first-stage nitrifiers & -0.376 \\
\hline Respiration rate heterotrophs, aerobic & 0.100 & Respiration rate algae & 0.373 \\
\hline Respiration rate heterotrophs, anoxic & -0.099 & Respiration rate first-stage nitrifiers & 0.328 \\
\hline Diffusion ammonium & 0.065 & Growth rate algae & -0.265 \\
\hline $\begin{array}{l}\text { Respiration rate heterotrophs, anoxic in } \\
\text { sediments }\end{array}$ & -0.060 & Growth rate second-stage nitrifiers & -0.237 \\
\hline Growth rate consumers in sediment & 0.059 & Growth rate heterotrophs, anoxic & 0.101 \\
\hline Growth rate algae & 0.048 & Respiration rate heterotrophs, aerobic & -0.093 \\
\hline Hydration rate in sediment & 0.043 & Sediment boundary layer & -0.085 \\
\hline Diffusion nitrite & 10.08 & & \\
\hline
\end{tabular}




\section{Conclusions}

The two main concepts in river water quality modelling in use today, QUAL2E and RWQM1 are here compared with regard to their role in management decisions. It is shown in this research that the focus for the two concepts is different. QUAL2E-based water quality models are mainly relating the algae processes towards the output where as the RWQM1 is also taking into account sedimentation and stresses processes performed separately by different microbial communities. As the microbial masses change between scenarios it can give better results to include them in the analysis. However, this only holds if sufficient measurement data are available for calibration and validation. If one needs to work with a restricted amount of data, the QUAL2E-based modelling will perform better.

When a RWQM1 model can be used that is well calibrated, it is best to choose a RWQM1 model over a QUAL2E-based model for evaluation of a scenario of reduced diffuse pollution as it was shown that the sediment processes become more important for such a scenario.

Sensitivity of the model results towards the processes is not the same for the two different river water quality modelling concepts and the different models are not always able to properly answer the same management problem. This clearly shows that managers should be aware of the possibilities and limitation of the model they use and chose a model that fits their problem and expectations. Also knowing which processes will become important after execution of a scenario can ensure that extra attention is paid towards those to obtain more reliable results. Here expert knowledge plays also an important role. In the Dender river case study the SA on the reduction scenario showed that the sediment and diffusion processes become more important.

\section{Acknowledgements}

The authors gratefully acknowledge the financial support of the EU Harmoni-CA project (EVKI-CT-2002-20003) and the EU CD4WC project (EVK1-CT-2002-00118).

\section{References}

Arnolds, J.G., Williams, J.R., Srivnivasan, R. and King, K.W. (1996). SWAT manual, USDA, Agricultural Research Service and Blackland Research Center, TX, USA.

Bervoets, L., Schneiders, A. and Verheyen, R.F. (1989). Onderzoek naar de verspreiding en de typologie van ecologisch waardevolle waterlopen in het Vlaams gewest. Deel 1 - Het Denderbekken, Universitaire Instelling Antwerpen, Belgium (in Dutch).

Brown, L.C. and Barnwell, T.O. (1987). The enhanced stream water quality models QUAL2E and QUAL2EUNCAS: documentation and user manual, Environmental Research Laboratory, US EPA, Athens, GA, USA.

Demuynck, C., Bauwens, W., De Pauw, N., Dobbelaere, I. and Poelman, E. (1997). Evaluation of pollution reduction scenarios in a river basin: application of long term water quality simulations. Wat. Sci. Tech., 35(9), 65-75.

McKay, M.D. (1995). Evaluating Prediction Uncertainty. US Nuclear Regulatory Commision and Los Alamos National Laboratory.

Reichert, P., Borchardt, D., Henze, M., Rauch, W., Shanahan, P., Somlyody, L. and Vanrolleghem, P.A. (2001). River water quality model No. 1 (RWQM1), IWA Publishing, London, UK.

Saltelli, A., Chan, K. and Scott, E.M. (eds) (2000). Sensitivity Analysis. Wiley, Chichester, UK.

van Griensven, A. and Bauwens, W. (2001). Integral water quality modelling of catchments. Wat. Sci. Tech., 43(7), 321-328.

van Griensven, A. and Bauwens, W. (2003). Multi-objective auto-calibration for semi-distributed water quality models. Wat. Resour. Res., 39(10), 1348-1358. 
van Griensven, A. and Bauwens, W. (2005). Application and evaluation of ESWAT on the Dender basin and the Wister lake basin. Hydrol. Processes, 19(3), 827-838.

van Griensven, A. and Vanrolleghem, P. (2005). Evaluation of river water quality model concepts used for river basin management. Proceedings of General Assembly of the European Geophysical Union, Vienna, Austria.

van Griensven, A., Francos, A. and Bauwens, W. (2002). Sensitivity analysis and auto-calibration of an integral dynamic model for river water quality. Wat. Sci. Tech., 45(9), 325-332.

Vandenberghe, V., Van Griensven, A. and Bauwens, W. (2001). Sensitivity analysis and calibration of the parameters of ESWAT: Application to the river Dender. Wat. Sci. Tech., 43(7), 295-301. 